\title{
Special section on Design, Test, Integration and Packaging of MEMS/MOEMS, 2013
}

\author{
Bernard Courtois
}

Published online: 13 December 2013

(c) Springer Science+Business Media New York 2013

The Symposium on Design, Test, Integration and Packaging of MEMS/MOEMS (DTIP) was held in Barcelona, Spain, 16-18 April 2013, as a follow up to previous issues held in Paris (1999, 2000), Mandelieu La Napoule (2001-2003), Montreux (2004, 2005), Stresa (2006, 2007), Nice (2008), Rome (2009), Seville (2010), Aix-en-Provence (2011), and Cannes (2012). This series of Symposia is a unique single-meeting event expressly planned to bring together participants interested in manufacturing microstructures and participants interested in design tools to facilitate the conception of these microstructures. The Symposium is traditionally composed of two conferences running in parallel: one on CAD, design and test, and another one on microfabrication, integration and Packaging. In addition, participants of both conferences can attend invited talks and special sessions.

This special issue is collecting reviewed and unabridged versions of papers presented at the Symposium. The papers have been again refereed, along the usual refereeing process in force at analog integrated circuits and signal processing. We are proud to offer these papers to the readers of this journal now.

From five revised papers submitted to this special section, three papers have been finally selected. They cover the modeling, simulation, optimization of three different types of MEMS devices: thermal accelerometers, electrothermal micromanipulators, RF switches.

We hope that you enjoy these contributions as much as we did.

B. Courtois $(\square)$

CMP, 46 avenue Félix Viallet, 38031 Grenoble Cedex, France

e-mail: Bernard.Courtois@imag.fr

URL: http://cmp.imag.fr

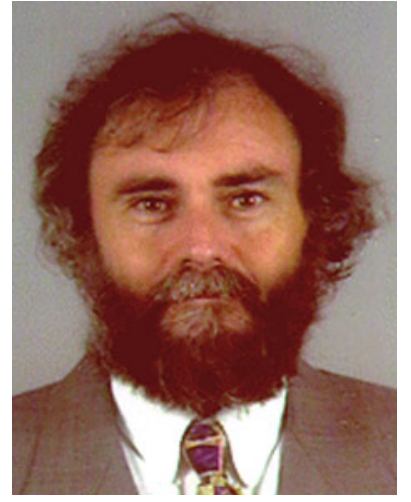

Bernard Courtois received the Engineer degree in 1973 from the Ecole Nationale Supérieure d'Informatique et Mathématiques Appliquées de Grenoble (Grenoble, France), and next the «Docteur-Ingénieur» and «Docteur-ès-Sciences» degrees from the Institut National Polytechnique de Grenoble. He served as Director of the CMP Service that is servicing Universities and Companies from about 70 countries for ICs, MCMs and MEMS prototyping and small volume production. He was also Director of the Laboratory of Techniques of Informatics and Microelectronics for Computer Architecture (TIMA) where researches include $\mathrm{CAD}$, architecture and testing of integrated circuits and systems. He has been general chair or program chair of various international conferences and workshops, including EDACETC-EUROASIC, Electron and Optical Beam Testing, EUROCHIP, Mixed-Signal Testing, Rapid System Prototyping, THERMINIC, Design, Test and Microfabrication of MEMS/MOEMS (DTIP), POLYTRONIC and European Nano Systems. He is a member of ACM, ASME, IEEE and IMAPS. He is a IEEE Computer Society's Golden Core member and he is Doctor Honoris Causa of the Technical University of Budapest. 